\title{
MICROSTRUCTURAL ADJUSTMENT OF THE DEGENERATED GRAPHITE LAYER IN DUCTILE IRON FOR TARGETED EVALUATION ON THE FATIGUE PROPERTIES
}

\author{
A. Kutz, P. Martin, and A. Bührig-Polaczek \\ Foundry-Institute RWTH Aachen University, Aachen, Germany
}

Copyright (c) 2020 The Author(s)

https://doi.org/10.1007/s40962-020-00455-w

\begin{abstract}
Graphite degeneration is the most prominent microstructural defect in the casting skin of ductile iron. Induced by either sulfur or oxygen contained in the molding material, its occurrence can be observed in a large range of iron castings, having substantial negative influences on the mechanical properties, especially fatigue resistance. Previous investigations predominately focused on the influence of the degenerated graphite layer, while accompanying changes of the iron matrix were neglected. The superposition of these effects hinders the evaluation of casting skin

casting skin. This approach is based on the application of a modified sand core coating. By adding sulfurizing additives to the coating and adjusting its binder content and viscosity, a predominately homogeneous degenerated layer of $0.5 \mathrm{~mm}$ thickness was obtained. Using specific heat treatment steps assured a fully ferritic or pearlitic iron matrix, isolating the degenerated layer as the main microstructural defect. Fatigue testing of these specimens will further enable the numerical evaluation of the fatigue resistance in dependence of the casting skin microstructure.
\end{abstract} defects in state-of-the-art design of ductile iron components. The presented solution utilizes an experimental procedure, which enables the production of specimens with specific, individual microstructural configurations in the
Keywords: cast iron, SGI, graphite degeneration, molding material, casting skin

\section{Introduction}

Design engineers are facing special challenges in the component layout of castings. In particular, the wall thickness dependence of the microstructure and thus the locally existing mechanical properties considerably complicate a reliable workpiece design and can lead to significant deviations between the simulation and the actually achieved properties of the component.

Especially for ductile iron, this situation is even more complex. In addition to the wall thickness dependence of the nodule count, the nodularity or the pearlite fraction, which all have a direct influence on the mechanical properties of the material, interactions between the melt and the molding material lead to the formation of a casting skin.

This paper is an invited submission to IJMC selected from presentations at the 6th Keith Millis on Ductile Iron held October 23-26, 2018, at the Sonesta Resort, Hilton Head Island, SC. It is published in the IJMC by permission of the DIS (Ductile Iron Society).
This general term includes not only surface roughness and near-surface nonmetallic inclusions but also irregularities in the microstructure at the edge of the casting.

The most prominent example of these microstructural defects is the degenerated graphite layer (DGL), also known as the degraded graphite layer. This defect is caused by the absorption of sulfur or oxygen during solidification and leads to the formation of a layer of lamellar graphite at the interface between the molding material and the melt. Since the DGL is induced by both sulfur-containing and oxygen-containing molding materials, it can be found in a wide variety of ductile iron castings, ranging from thinwalled automotive components to hand-molded heavy casting parts.

While the causes for the formation of DGLs have been characterized to a reasonable extent, only very few studies on their influence on mechanical properties have been published. ${ }^{1-4}$ The static mechanical properties are only slightly influenced by the DGL; however, a significant 
negative influence on the fatigue resistance properties of ductile iron $^{4}$ can be seen. This is particularly critical for modern, service life-based approaches to component design, as reliable material data and a well-founded knowledge of cyclic material behavior are crucial for a reliable and efficient design process.

At this point, the transfer of the existing research results regarding the influence of the DGL on mechanical properties into component design is difficult. On the one hand, the amount of data and investigations for various cast iron alloys is very limited. The second challenge is illustrated in the micrographs in Figure 1. The thickness of the DGL can vary greatly within small component areas. Also, with the formation of the DGL further changes in the microstructure of the casting skin are induced, which can be seen from the alteration in the iron matrix on the micrograph to the right, leading to a highly complex microstructure in the casting skin of technical ductile iron components.

These complex casting skin configurations prevent a reliable estimation of the actual fatigue resistance and therefore inhibit the numerical verification of the structural durability of ductile iron castings with a DGL. In current practice, this issue is addressed by high safety factors for component design and extensive component testing. This reduces the lightweight potential and the cost and time efficiency of the design process for ductile iron castings.

In order to predict the influences of the DGL on the fatigue properties correctly and to ensure a solid and efficient component design, it is essential that the influences of the individual, isolated defects are investigated and understood. To make this possible, fatigue testing must be conducted on "ideal samples," which contain only one variant of the DGL. Thus, the unintentional measurement of microstructural cross-influences as they occur with industrial samples is avoided.
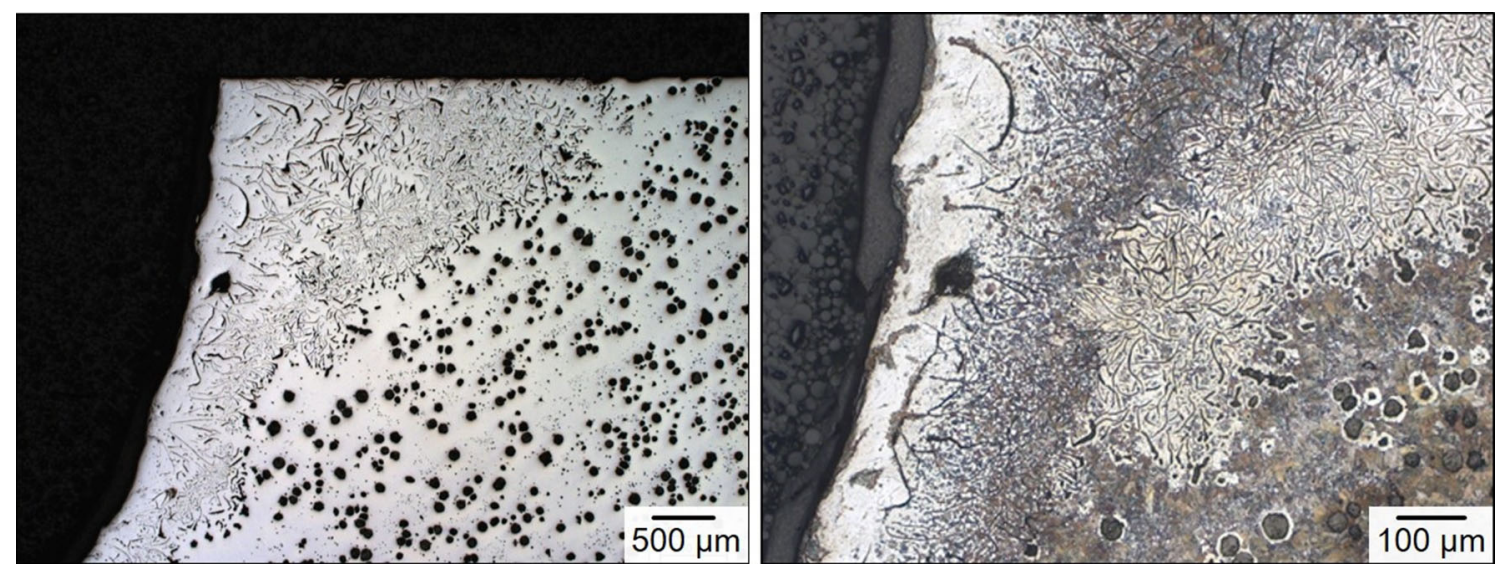

Figure 1. Microstructure of an EN-GJS-700-2 casting showing the formation of a substantial DGL in the polished micrograph (left) and complex changes of the iron matrix within the DGL after Nital etching (right).
Subsequent research will use the obtained material data and knowledge about the influence of individual defects on fatigue resistance for the development of numerical models enabling the prediction of the fatigue strength of cast iron components in regard to the isolated, individual defects. Further on, these individual models will be merged, allowing the estimation of the structural durability for ductile iron castings with complex casting skin microstructures.

This study gives a short introduction to the formation of DGLs in ductile iron and a quick overview of the effects of different molding materials in this regard. The development of the test geometry, the selection and adjustment of the molding material and the casting experiments are described afterward, before the results are presented and discussed and a conclusion is drawn. The future fatigue tests of the samples and the development of a numerical model, which enables the calculation of the influence of casting skin on cyclic material properties, will be conducted at the Technische Universität Darmstadt and the Fraunhofer Institute for Structural Durability and System Reliability LBF in Darmstadt, Germany, and are therefore not the subject of this study.

\section{Literature Background}

\section{Formation of the Degenerated Graphite Layer}

In spheroidal cast iron (SGI), the eponymous shape of the carbon phase is achieved by magnesium treatment of the melt. Magnesium causes the formation of graphite spheres through the binding and removal of oxygen and sulfur from the melt. In particular, sulfur strongly promotes the formation of graphite flakes, making its elimination from the molten metal inevitable for the production of ductile iron. ${ }^{5}$ In addition, past studies have shown that spheroidization is not only caused by the absence of sulfur, but also that the 
residual magnesium content in iron supports the formation of graphite spheroids during solidification furthermore. ${ }^{6}$

If the required magnesium content is reduced due to external influences, it can lead to degeneration of graphite and therefore to the creation of flake graphite. The most common example of an external influence regarding the casting skin is the binding of magnesium at the interface between the molding material and the melt by sulfur or oxygen. During mold filling and solidification, a thermally activated interaction at this interface will take place. Sulfur- or oxygen-containing molding material components form intermediate products during their thermal decomposition which are absorbed by the melt. The sulfur or oxygen atoms dissociate completely in the melt and react with the magnesium, which leads to the formation of $\mathrm{MgS}$ or $\mathrm{MgO}$. The magnesium content in the liquid metal near the molding material therefore gradually fades causing formation of the DGL. As a result, the thickness of the DGL can amount up to several millimeters below the casting surface, accompanied by negative effects on the mechanical properties of the casting. ${ }^{\text {? }}$

Since the reactions are thermally activated and sustained, the thickness of the DGL layer produced depends on the thermal properties of the mold. For larger wall thicknesses and hence longer cooling rates, the molding material has more time to deliver sulfur/oxygen into the melt and consequently to create a thicker DGL. ${ }^{8,9}$

Depending on the residual magnesium content of the melt, the effect of sulfur or oxygen introduced via the molding material varies. Cast iron materials such as compacted graphite iron with a low residual-magnesium content tend to form a thicker layer of graphite lamellae on the meltmold interface, since the critical $\mathrm{Mg}$ content which leads to flake graphite formation is reached much faster and further into the base microstructure. SGI, on the other hand, has a lower tendency for the formation of flake graphite due to its higher residual-magnesium content. ${ }^{10}$

\section{Influence of Molding Materials}

\section{Sulfur-Containing Molding Materials}

In cold-setting, organic binder systems, like commercially used furan and phenolic resins, the hardener is the primary source of sulfur in the molding material. It often contains large amounts of para-toluenesulfonic acid (PTSA), which forms $\mathrm{SO}_{2}$ during its thermal decomposition causing the creation of the DGL. ${ }^{11}$

The presence of oxygen can have an additional negative effect on this reaction since it oxidizes $\mathrm{MgS}$ which leads to renewed release of sulfur and further increases the depletion of magnesium. ${ }^{12}$ Another effect to consider when using PTSA-containing hardeners is the enrichment of sulfur in reclaimed sand. Since sulfur is not completely removed from the molding material during conventional mechanical sand refining processes, its content will be continuously enriched within the sand regenerate. Without continuous additions of fresh sand to the reclaimed sand, the formation of large DGLs is very likely to occur. ${ }^{1,13}$

\section{Oxygen-Containing Molding Materials}

The most commonly used molding material holding water is green sand. Due to the thermal stress during mold filling and solidification, the water in green sand can dissociate and oxygen is released into the melt, forming flake graphite. Further on for the particularly thin-walled Croning shell molds, oxygen can diffuse through the mold to the boundary between melt and molding material again causing DGL formation. ${ }^{7}$

\section{Sand Core Molding Materials}

The organically bound molding materials usually used in sand core production processes such as cold-, warm- or hot-box core shooting do not contain significant amounts of sulfur or oxygen. In these systems, nitrogen is suspected to promote degeneration of graphite. However, the effect here is considerably lower than the effects of sulfur or oxygen. ${ }^{7}$

\section{Experimental Procedure}

\section{Casting Geometry}

Cast iron bars with a length of $205 \mathrm{~mm}$, a width of $28 \mathrm{~mm}$ and a height of $30 \mathrm{~mm}$ were needed for the production of fatigue samples. The DGL will be generated on the bottom interface of the casting between the melt and the sand core, depicted in Figure 2. This ensures that possible nonmetallic inclusions in the melt will rise to the top and will not affect the fatigue specimens. To prevent porosity and to homogenize the cooling rates in the area of the fatigue specimens, two different sizes of exothermic riser sleeves were used.

An excerpt from the casting geometry and the schematic position of the fatigue samples is shown in the right image of Figure 2. Flat specimens will be cut from the DGL and the overlying basic microstructure and thus allow a characterization of the fatigue properties of the basic microstructure and the DGL itself separately. Based on these data, the numerical layer model to be developed by the research partners should enable a determination of fatigue resistance for the entire microstructure (bulk material + DGL). The bending specimens contain the nodular bulk microstructure and the DGL. Their fatigue 

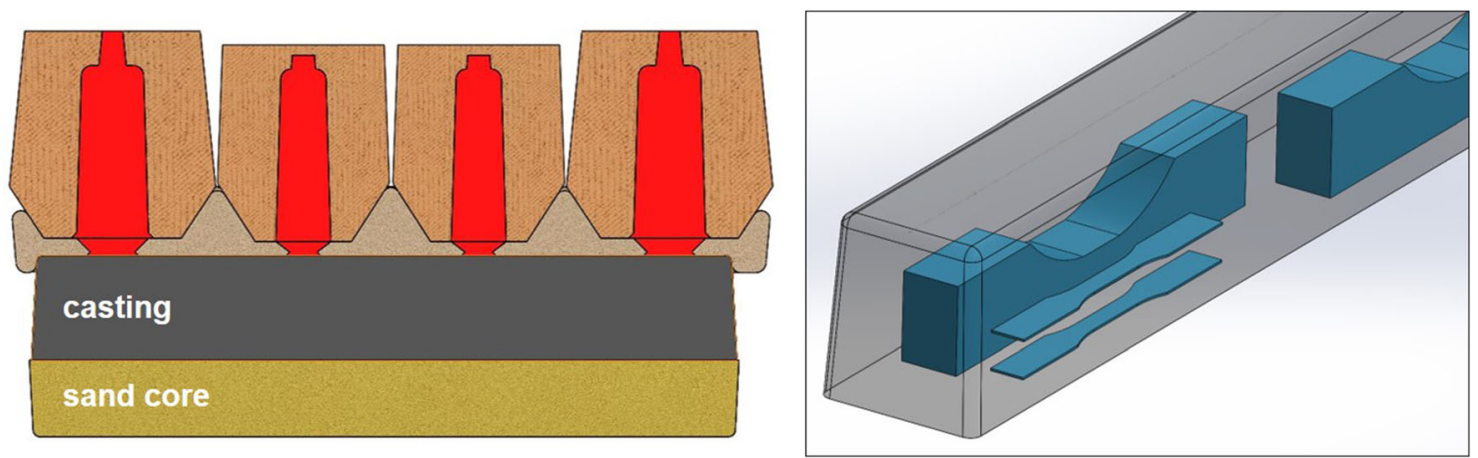

Figure 2. Schematic cross section of a cast iron sample with red-marked risers and attached exothermic riser sleeves (left); visualization of the fatigue testing specimen location within the front of a cast iron sample (right).

testing serves to examine properties of the entire microstructure and to validate the numerical model.

For identical casting and cooling conditions, 14 samples were merged circularly into the final casting geometry shown in Figure 3. The number of samples per casting was limited by the maximum melting capacity of the furnace and the mold size which had to be formed and moved manually. The gating system was designed to establish a slow (simulated melt velocity at gate $<0.2 \mathrm{~m} / \mathrm{s}$ ) and smooth flow of the melt to prevent the formation of dross and erosion of molding material. After prototype experiments, overflow runners were added to the edges of the samples to ensure a smoother mold filling and the collection of possible detached nonmetallic particles from the sand cores.

\section{Systematical Formation of the Degenerated Graphite Layer}

The casting geometry allowed an examination of a range of possible sulfur- or oxygen-containing molding materials and core coatings to achieve a homogeneous DGL, while the main body of the mold could conveniently be manufactured by hand using furan resin. Because the minimum manufacturable thickness of the flat specimens is $400 \mu \mathrm{m}$, a targeted thickness of $500 \mu \mathrm{m}$ for the DGL was chosen.

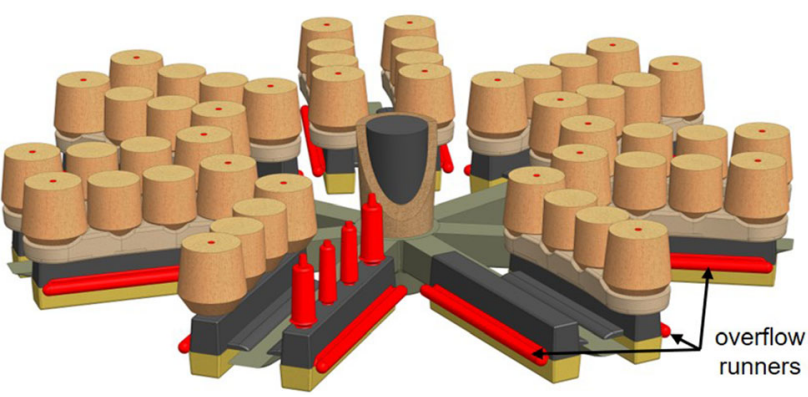

Figure 3. Overview of the final test geometry including over flow runners.
The full description of the molding material pretests goes beyond the scope of this work. Therefore, a selection of pretest results that determined the further choice and adjustment of the molding material is outlined below:

- Conventional furan-based binder with high amount of sulfuric acid did not show a significant formation of a DGL due to the rather low thermic modulus of the castings.

- The addition of oxygen carriers like potassium peroxide sulfate or potassium permanganate to the molding materials and coatings showed the formation of DGL but was accompanied by strong porosity at the casting surface.

- The introduction of sulfur powder or pyrite powder into sand core coatings showed the most promising results and was further investigated.

Based on these results, a cold-setting polyurethane binder was chosen for the production of the sand cores. For the adjustment of the DGL, an alcohol-based aluminum-silicate coating was chosen, which was mixed with sulfur powder. In order to prevent erosion of the coating and thus an irregular DGL thickness (Figure 4), the sulfur content of the coating was varied and additional binder was added to the coating. The addition of binder became necessary as the specific surface of the solids in the coating increases with the addition of sulfur powder. To achieve an equal abrasion resistance to conventional core coatings, it is crucial to increase the binder content of the slurry to prevent erosion during mold filling.

The final composition of the sand cores and the sulfur coating is shown in Table 1 . The viscosity of the coating was measured and adjusted using a 4-mm standard flow cup, and the sand core was dipped for $1 \mathrm{~s}$ leading to a coating thickness between 150 and $200 \mu \mathrm{m}$. Further on, the coated sand cores were dried for $1 \mathrm{~h}$ at $100{ }^{\circ} \mathrm{C}$ in a heat treatment oven before placed into the main body of the furan mold. 


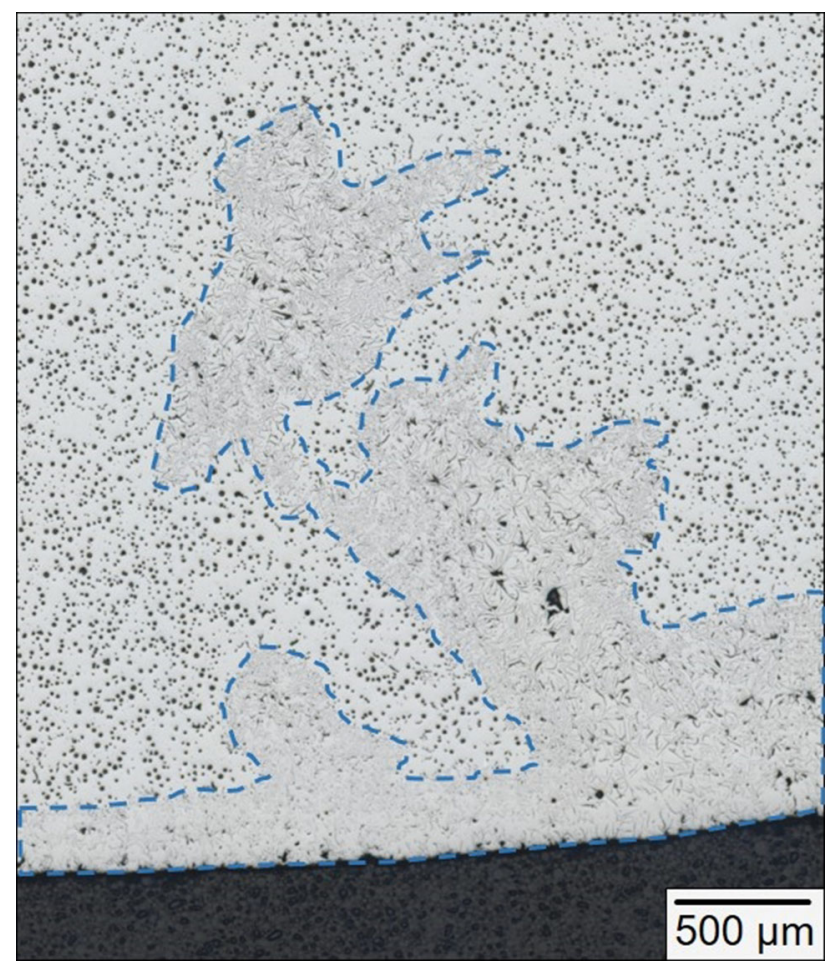

Figure 4. Micrograph in polished state of the DGL (blue dashed line) generated by the addition of $20 \mathrm{w} . \mathrm{\%}$ of sulfur powder to the core coating without the addition of binder to the coating.

Table 1. Final Composition of the Utilized Sand Cores and the Applied Sulfur Coating

\begin{tabular}{|c|c|c|c|}
\hline \multicolumn{2}{|c|}{ Sand cores } & \multicolumn{2}{|l|}{ Sulfur coating } \\
\hline Base & Additives & Base & Additives \\
\hline \multirow[t]{2}{*}{$\begin{array}{l}\text { Silica } \\
\text { sand }\end{array}$} & $\begin{array}{l}+0.8 \text { wt } \% \\
\text { phenolic resin }\end{array}$ & $\begin{array}{l}\text { Alcohol-based } \\
\text { aluminum- } \\
\text { silicate coating }\end{array}$ & $\begin{array}{l}+8.5 \text { wt } \% \\
\text { sulfur } \\
\text { powder }\end{array}$ \\
\hline & $\begin{array}{l}+0.8 \text { wt } \% \\
\text { polyisocyanate }\end{array}$ & & $\begin{array}{l}+8.5 w t \% \\
\text { coating } \\
\text { binder }\end{array}$ \\
\hline
\end{tabular}

\section{Casting Experiments}

EN-GJS-400-15 and EN-GJS-700-2 were selected as materials for the casting trials to show the influence of the DGL on the most widespread commercially used ferritic and pearlitic ductile iron grades. For each of the alloys, a casting without DGL, a casting with DGL in the as-cast state and a casting with DGL in an annealed state were produced. The aim of the heat treatment was to eliminate changes in the iron matrix and to achieve a complete ferritic or pearlitic microstructure. This allowed an isolated observation of the influence of the DGL. The designations for the six castings are shown in Table 2.
Table 2. Overview of the Performed Casting Experiments and Selected Experimental Variations

\begin{tabular}{|c|c|c|c|c|}
\hline $\begin{array}{l}\text { Casting } \\
\text { ID }\end{array}$ & Alloy & $\begin{array}{l}\text { Sulfur core } \\
\text { coating }\end{array}$ & DGL & State \\
\hline W_I & $\begin{array}{c}\text { EN-GJS- } \\
400-15\end{array}$ & No & No & As-cast \\
\hline GE_I & $\begin{array}{c}\text { EN-GJS- } \\
400-15\end{array}$ & Yes & Yes & As-cast \\
\hline GE_II & $\begin{array}{c}\text { EN-GJS- } \\
400-15\end{array}$ & Yes & Yes & Ferritization \\
\hline W_II & $\begin{array}{c}\text { EN-GJS- } \\
700-2\end{array}$ & No & No & As-cast \\
\hline GE_III & $\begin{array}{c}\text { EN-GJS- } \\
700-2\end{array}$ & Yes & Yes & As-cast \\
\hline GE_IV & $\begin{array}{c}\text { EN-GJS- } \\
700-2\end{array}$ & Yes & Yes & Pearlitization \\
\hline
\end{tabular}

SGI feeder material, iron and copper (for the pearlitic grades) were melted in a graphite crucible using a $50-\mathrm{kg}$ induction furnace. The carbon content was adjusted by the addition of a carburizing agent made from amorphous acetylene coke. At $1500{ }^{\circ} \mathrm{C}$, the crucible was taken out of the furnace for magnesium treatment via immersion bell. After deslagging, the inoculant was added to the melt and a spectroscopic sample was taken. Afterward, the melt was poured at a pouring temperature of $1350{ }^{\circ} \mathrm{C}$. The chemical analysis for the six castings is shown in Table 3 .

The chemical composition of the casts shows a predominantly homogeneous profile. Larger deviations can be seen primarily in the silicon content, with the samples GE_I and GE_II deviating downwards and the sample GE_III upwards in this regard. The carbon equivalent was deliberately set hypereutectic to achieve, despite the decoupled growth of the SGI eutectic, a predominantly eutectic structure for the rather high cooling rate of the casting specimens. The shown deviations were rated as tolerable, and the chemical composition of the castings was therefore assessed as comparable.

\section{Postprocessing and Heat Treatment}

To minimize the formation of internal stresses during cooling, the casting was left in the mold until room temperature was reached. After demolding, cutting and grinding, the surface was cleaned lightly by using an electrical wire brush. The samples were not sandblasted to again avoid the introduction of residual stresses into the casting skin during postprocessing.

To compensate for possible changes in the iron matrix, which may occur in the as-cast state, and to allow isolated observation of purely ferritic or purely pearlitic samples 
Table 3. Chemical Composition of the Castings Determined by Spark Spectrometer; for a More Accurate Measurement the Carbon Content Was Determined Via Combustion Method; ${ }^{*}$ Calculated with $C E=C+(S i+P) / 3$

\begin{tabular}{lllllllll}
\hline Casting ID & $\mathrm{C}$ & $\mathrm{Si}$ & $\mathrm{Mg}$ & $\mathrm{Cu}$ & $\mathrm{Mn}$ & $\mathrm{S}$ & $\mathrm{P}$ & $\mathrm{CE}^{*}$ \\
\hline W_I & 3.72 & 2.66 & 0.034 & 0.062 & 0.120 & 0.009 & 0.011 & 4.61 \\
GE_I & 3.76 & 2.45 & 0.032 & 0.065 & 0.168 & 0.009 & 0.029 & 4.57 \\
GE_II & 3.64 & 2.47 & 0.028 & 0.066 & 0.138 & 0.008 & 0.022 & 4.47 \\
W_II & 3.68 & 2.64 & 0.039 & 0.697 & 0.126 & 0.010 & 0.029 & 4.57 \\
GE_III & 3.65 & 2.85 & 0.045 & 0.735 & 0.136 & 0.009 & 0.027 & 4.61 \\
GE_IV & 3.68 & 2.63 & 0.036 & 0.753 & 0.146 & 0.009 & 0.028 & 4.57 \\
\hline
\end{tabular}

with DGL, the samples GE_II and GE_IV were subsequently heat-treated. Several annealing temperatures and times were tested in order to achieve the desired microstructural characteristics. Figure 5 shows on the lefthand side the temperature curve of the heat treatment furnace for the ferritization heat treatment of castings GE_II. At $760{ }^{\circ} \mathrm{C}$, the annealing temperature is in the subcritical area to avoid austenitization and prohibit the affiliated change of the graphite morphology.

In addition, stress-relief annealing at $550{ }^{\circ} \mathrm{C}$ was carried out downstream of the main annealing process. For the pearlitization of GE_IV, the samples were placed in a preheated resistance furnace at $1000{ }^{\circ} \mathrm{C}$, removed after $10 \mathrm{~min}$ and air-cooled. Except for GE_II, all specimens were separately stress-relief heat-treated to minimize any residual stresses that could affect future fatigue tests. The temperature curve of stress-relief annealing is shown in Figure 5 on the right.

\section{Metallographic Analysis}

One random specimen per casting was used for metallographic analysis. The positions for the sections are shown in Figure 6. In relation to the flow direction of the melt, $A$ indicates the inner, $M$ the middle and $E$ the outer sample location. By using a casting simulation, the local solidification time and cooling rate for the central metallographic position $M$ could be estimated at $250 \mathrm{~s}$ and $2.4 \mathrm{~K} / \mathrm{s}$ and for the outer positions $A$ and $E$ at $220 \mathrm{~s}$ and $2.7 \mathrm{~K} / \mathrm{s}$.

The specimens were embedded, ground and polished. Micrographs were taken in the polished and etched states. The etchant used was 3\% Nital. To account for the inhomogeneities of the DGL, the depth of the layer was measured in equal distances over the entire width of the section as it is also shown in Figure 7.

For the digital image analysis of the base material, five images were taken per metallographic section at $100 \times$ magnification in the polished state. The images were taken at a distance of 4-6 $\mathrm{mm}$ from the casting skin, since this roughly corresponds to the extraction positions for the flat fatigue testing specimens of the basic microstructure. The image resolution was $2600 \times 2060$ pixels. The nodularity of the microstructures was determined following the ASTM E2567 standard. ${ }^{14}$
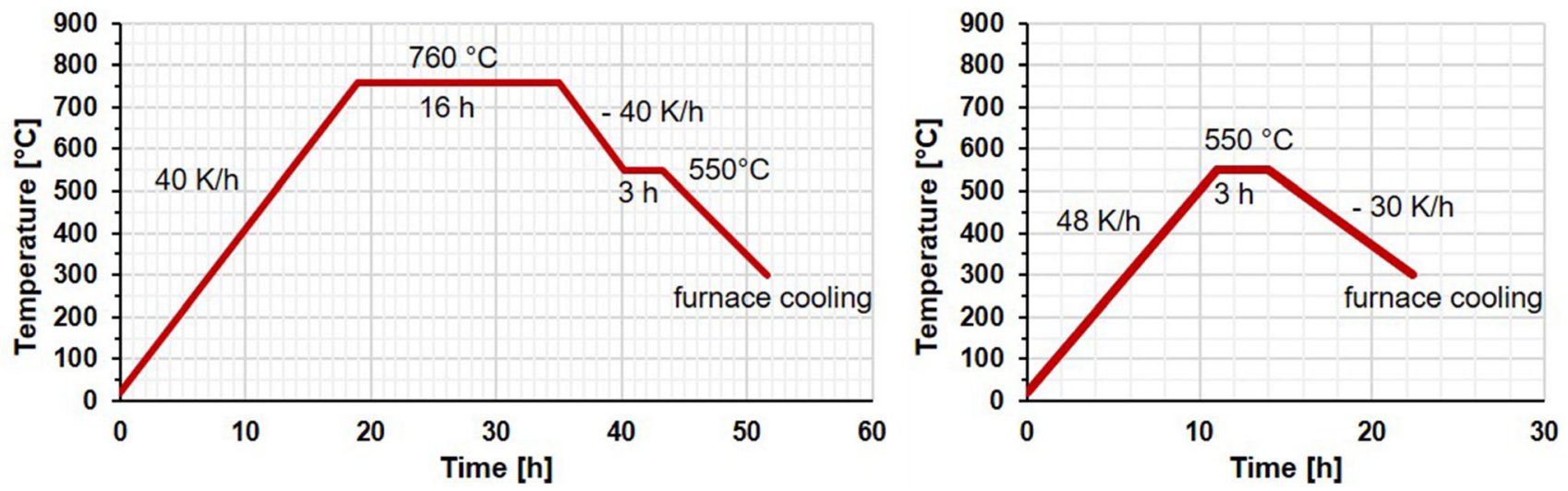

Figure 5. Temperature curves for the ferritization (left) and the stress-relief annealing (right). 


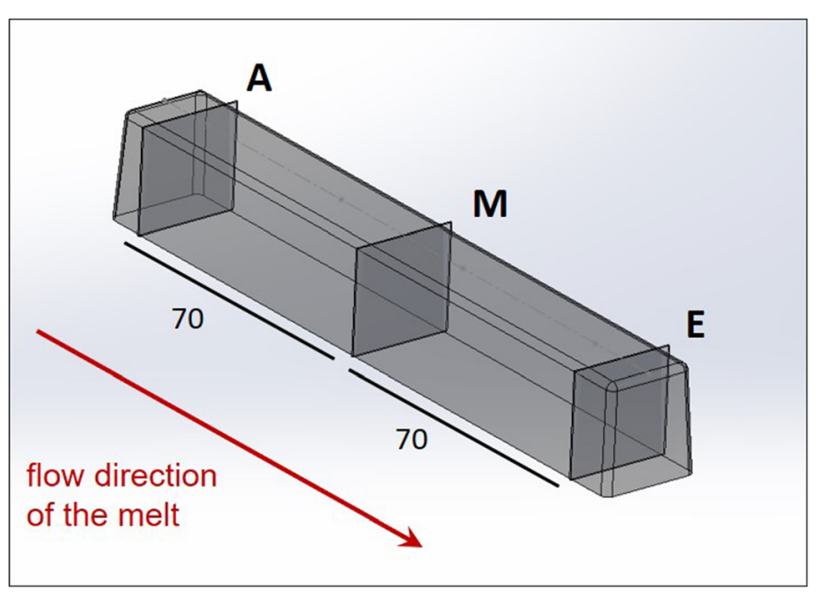

Figure 6. Position of metallographic sections in relation to the direction of melt flow.

\section{Results and Discussion}

\section{Graphite Morphology}

The base material samples W_I and W_II are not considered at this point, since without the use of the sulfur coating they did not show any significant formation of lamellar graphite in the casting skin. Figure 8 shows the casting skin microstructure and the included DGL for specimen GE_I. The transition from the basic nodular structure to the lamellae of the DGL is very distinct and located at $500 \mu \mathrm{m}$ from the edge. The other samples also showed a comparable characteristic of the DGL and the basic microstructure.

While the basic microstructure has a very homogeneous nodular appearance, this is not the case for the graphite flakes of the DGL. Especially near the casting edge, massive graphite lamellae can be seen, which can be classified in the category of A-type graphite. The graphite tends to appear in a finer form (D-type) directly at the boundary between the DGL and the basic microstructure. This observation is predominantly consistent with the literature. ${ }^{7}$ The transition of graphite morphology is caused by the depletion of sulfur and thus the enrichment of magnesium toward the center of the sample. Contrary to the source, the formation of compacted graphite between the nodular basic microstructure and the graphite lamellae of the DGL cannot be observed.
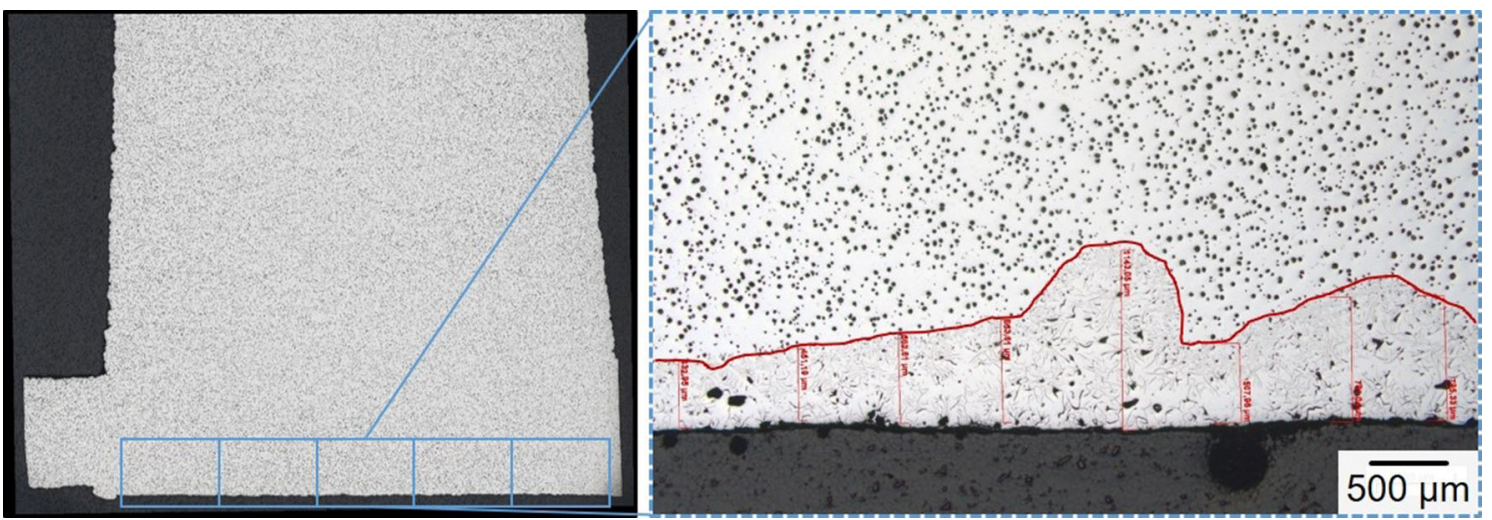

Figure 7. Depiction of the measuring method for the determination of the DGL thickness (red) in the entire metallographic section; per casting sample five micrographs were taken and examined.

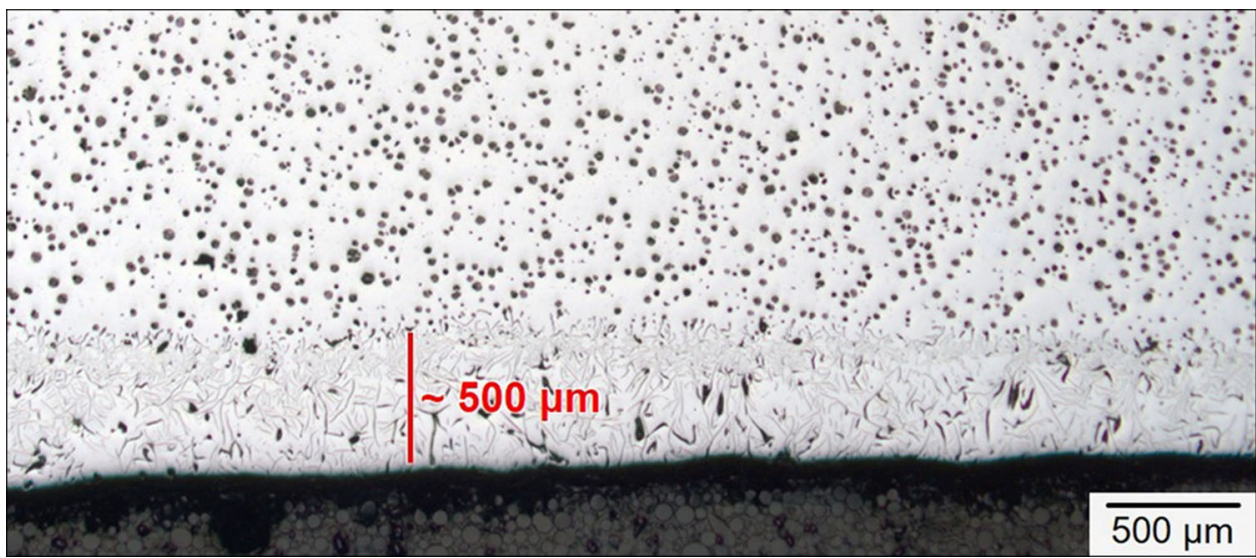

Figure 8. Polished micrograph of the set DGL of casting GE_I. 


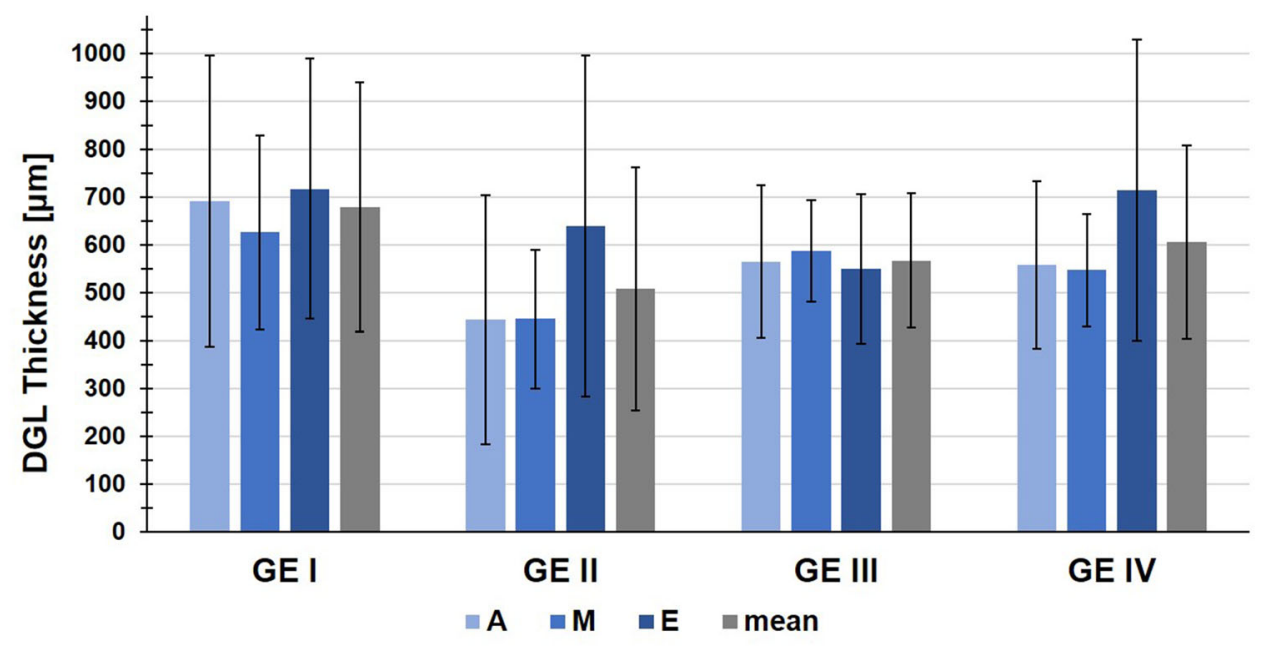

Figure 9. Average thickness of the DGL for all castings and individual metallographic section positions; the error indicators display the standard deviations.

To evaluate the homogeneity and overall values of the achieved DGL for the individual castings, the results of the measurement are summarized in Figure 9 for different metallographic positions and the overall mean value of the castings. Most of the samples show a degeneration at a similar level slightly above $500 \mu \mathrm{m}$ with GE_I depicting the highest overall values and GE_II at the lower end with the thickness of the DGL falling under $500 \mu \mathrm{m}$ in positions A and M. The most likely explanation for this is a slight formation of scale during the annealing process for this sample. Due to the oxidation of the outer layer of the casting in the heat treatment furnace, the DGL is gradually converted into a scale layer, thus reducing the effective thickness of the DGL. While the stress-relief heat treatment carried out on all samples only took place at low temperatures and thus caused no significant scaling, the GE_IV sample is only annealed over a very short period, so that no significant oxidation could be observed here either.
While strong degenerations above $1 \mathrm{~mm}$ could be avoided, the samples show quite significant variations in the layer thickness of the DGL, which are represented by the standard deviation. No correlation between the position of the metallographic section and the inhomogeneity of the DGL can be seen.

The nodularity measured by digital image analysis exhibited an average level of $\sim 80 \%$ for all samples as shown in Figure 10. Between W_I and W_II, which were produced without the sulfur coating, and the remaining castings, there is no apparent systemic difference. The slightly lower value for GE_II is predominantly caused by low residualmagnesium content of $0.028 \mathrm{wt} \%$, which is shown in Table 3. An influence by the ferritization cannot be completely ruled out but should only be of minor concern. Due to the fact that the subcritical annealing temperature does not induce the formation of austenite, the carbon atoms can

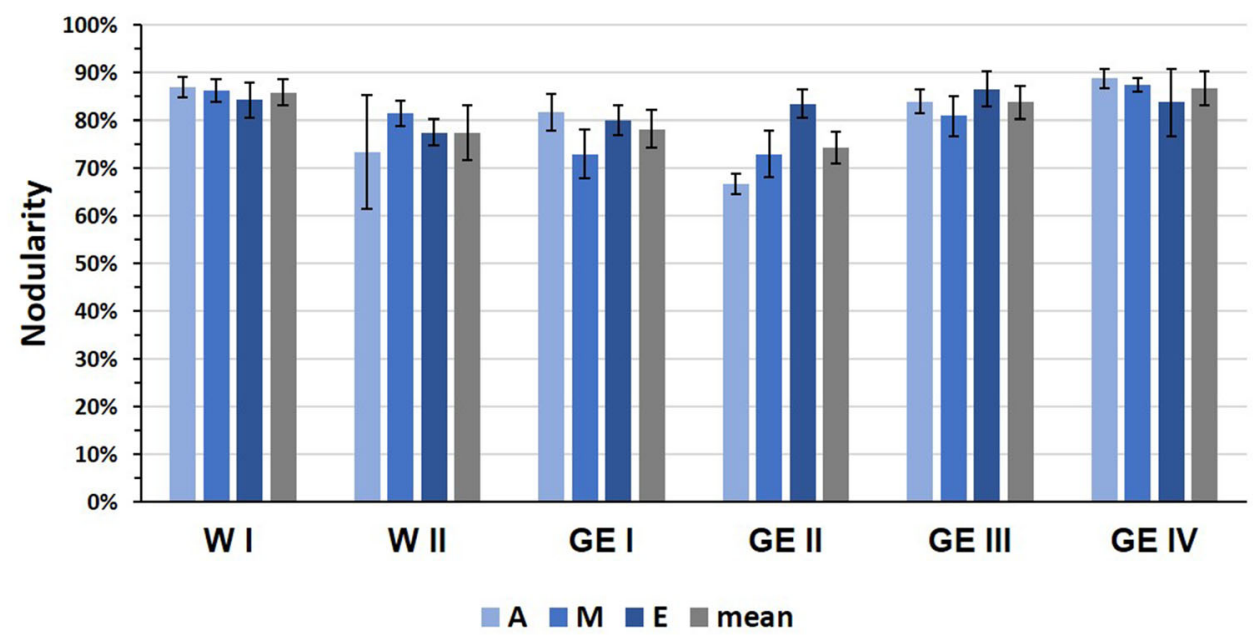

Figure 10. Nodularity determined with the aid of digital image analysis for all castings and individual metallographic section positions; the error indicators display the standard deviations. 
only crystallize very slowly and evenly onto the existing graphite particles. In addition, the predominantly ferritic microstructure only contains very small amounts of carbon that could influence the graphite morphology.

Substantial degenerations over $1 \mathrm{~mm}$ were suppressed by the aimed configuration of the sulfur coating and the slow mold filling through the gating system. This ensures a low release of sulfur into the melt during the filling process, so that the basic structure remains unaffected and the formation of the graphite lamellae is limited to the outer region of the samples. This statement is supported by the constant level of nodularity in the castings.

The dissociation of sulfur into the melt after mold filling and subsequent solidification could not be controlled more strongly. Even with a completely homogeneous distribution of the sulfur particles in the coating, convection occurs within the mold during solidification and therefore also at the contact surface between the liquid metal and the core coating. Small turbulences of the melt carry the sulfur out of the coating to varying degrees and dissolve it unevenly near the melt-mold interface before solidification. In addition, small, unavoidable deviations of the core coating thickness must be considered. In summary, these effects explain the variations in layer thickness of the DGL.

\section{Iron Matrix}

All the EN-GJS-400-15 castings show a ferritic matrix in the bulk material as shown in Figure 11. In the DGL of GE_I, the formation of pearlite can be observed, while this effect was reversed through the ferritization of specimen GE_II resulting in a fully ferritic matrix in between the graphite lamellae. Depending on the thickness of the DGL, the graphite flakes exceed the pearlitic zone by 50-100 $\mu \mathrm{m}$.

The formation of pearlite in the as-cast sample GE_I is consistent with the current literature. During eutectic solidification, the sulfur of the sand core coating is absorbed by the melt and inhibits the formation of nodular graphite and also dissolves in the iron matrix. This amount of dissolved sulfur has a strong pearlite forming effect which clearly shows in the microstructure of GE_I. As claimed by Stefanescu et al., ${ }^{9}$ this seems to be mainly due to the cooling through the A1 temperature, which is influenced by the sulfur content of the casting skin. This also offers a possible explanation for the unusually long annealing time required for complete ferritization of the casting GE_II. The sulfur dissolved in the matrix seems to strongly restrict the mobility of the carbon atoms. Therefore, for a complete decomposition of the cementite lamellae via diffusion at a constant annealing temperature, a longer annealing time is required.
There are two possible explanations for the formation of the protruding ferritic flake graphite layer. The depth of action of sulfur in the liquid metal is limited by the convection of the melt and the diffusive boundary conditions. As a result, there is enough sulfur in the outer area to bind the magnesium and therefore force the development of graphite lamellae, while on the other hand there is not enough sulfur left to promote pearlite formation in the matrix, thus resulting in a ferritic microstructure. In addition, the transition of the graphite structure from A- to D-type flakes at the interface of the bulk microstructure and the DGL could be relevant. The low distances between the graphite lamellae in finer D-type microstructure lead to smaller diffusion paths. The carbon atoms released during the eutectoid decomposition of austenite must therefore move over smaller distances to reach the next graphite particle. With the previously described simultaneous decrease in sulfur content and the associated higher carbon activity, this would adequately explain the complete formation of ferrite in this area.

The base sample W_II for EN-GJS-700-2 shows a predominantly pearlitic microstructure caused by the targeted addition of copper, as shown on the right-hand side of Figure 11. While GE_III shows a similar picture, a higher proportion of ferrite in the microstructure can be observed due to the high-Si content. Due to the pearlitization, the heat-treated casting GE_IV shows the highest amount of pearlite in the main microstructure.

Similar to the EN-GJS-400-15 castings, a ferritic flake graphite layer is protruding into the main microstructure of the pearlitic DGL. Again, this ferritic layer shows a graphite morphology comparable to D-type flake graphite. The thickness of this ferritic flake graphite layer again corresponds to the general thickness of the DGL. Even longer pearlitization heat treatments were not able to generate a fully pearlitic matrix in the DGL of GE_IV. This reinforces the explanation already formulated for the EN-GJS-400-15 castings. Even in the presence of another pearlitic stabilizing element such as copper and the increased cooling rates during the air cooling of the samples after austenitization, the diffusion conditions due to the fine D-type flake graphite were sufficient enough to ensure the formation of ferrite in the intermediate layer. Furthermore, a depletion of other pearlite-stabilizing or the enrichment of ferritestabilizing elements in the area of the ferritic flake graphite layer is conceivable. These differences in local chemical composition could be caused by segregation effects during eutectic solidification of the nodular graphite and flake graphite areas and require further investigation.

During the examination of the etched specimens of casting GE_II, precipitants in the DGL were detected, which are shown in Figure 12. It was assumed that it was cementite, which was not dissolved during the heat treatment due to the low, subcritical annealing temperature and remained in 

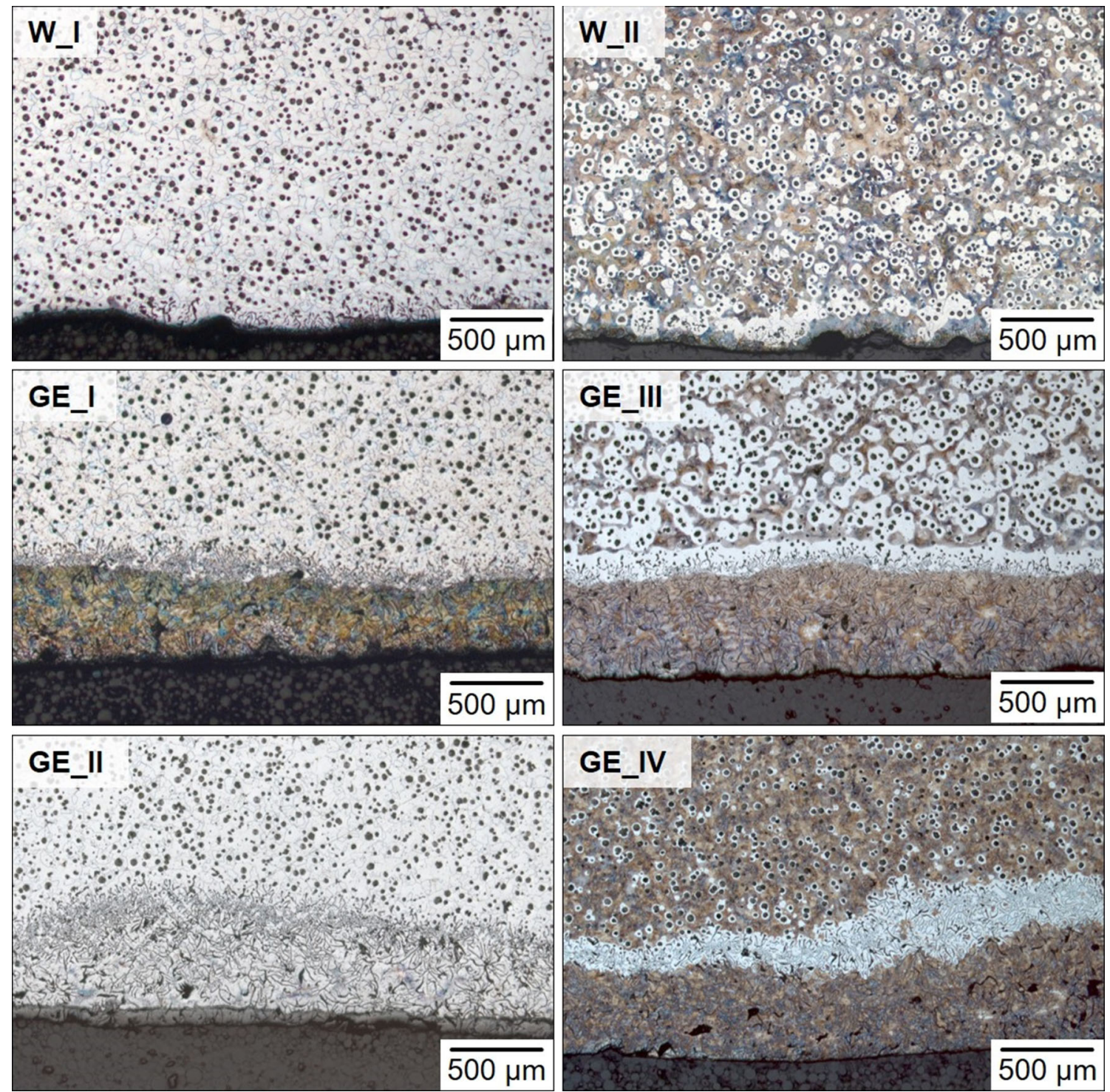

Figure 11. Etched micrographs of the ferritic EN-GJS-400-15 castings (left column) and the pearlitic EN-GJS-700-2 castings (right column).

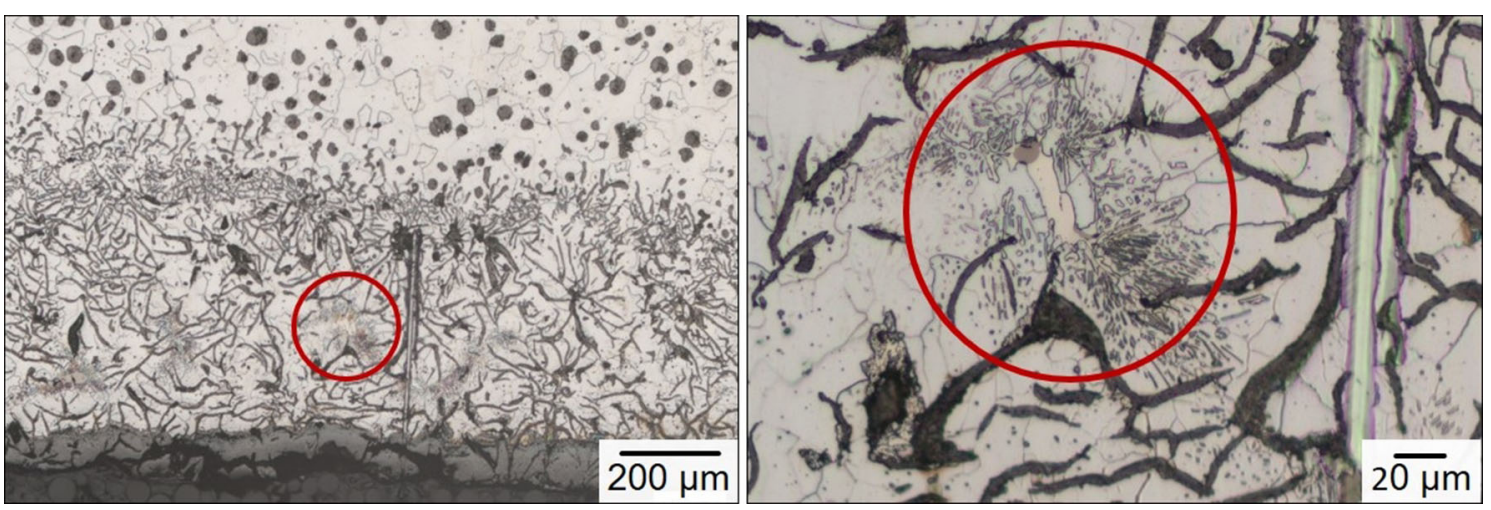

Figure 12. Micrograph of specimen GE_I showing the position (left) and the morphology (right) of cementite particles in the DGL. 


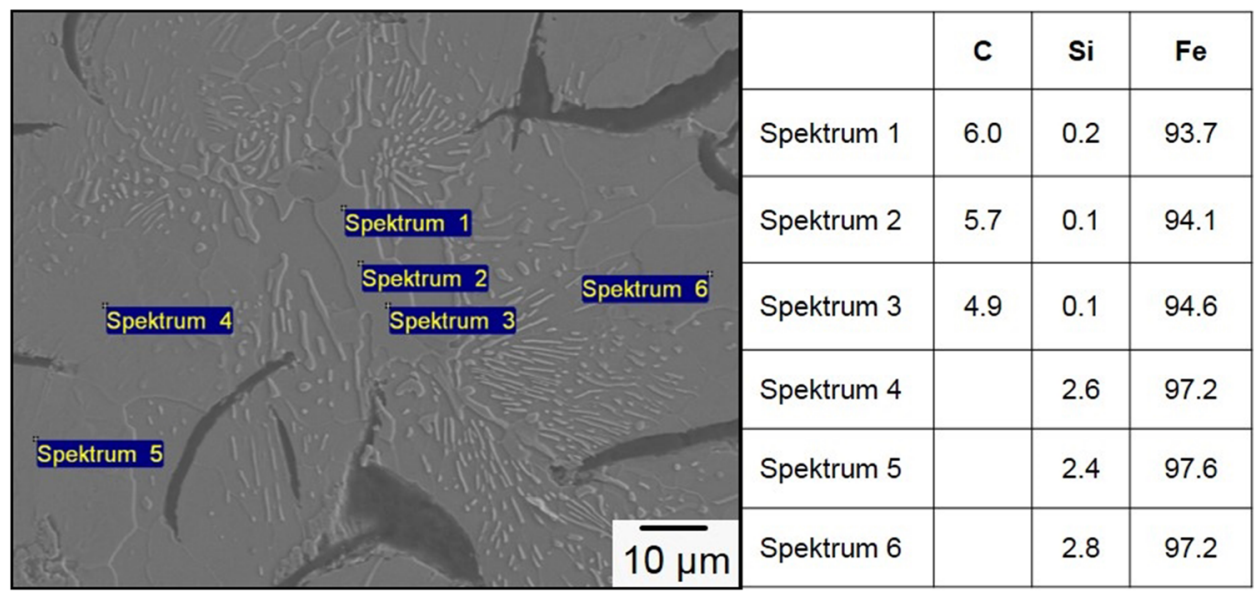

Figure 13. EDX measurement of the precipitant shown in Fig. 12 in \% by mass. Measurement points "Spektrum" 1, 2 and 3 were performed on the precipitant, while points 4, 5 and 6 cover the surrounding iron matrix. In the latter cases, small carbon peaks could be attributed to sample contamination during measurement and were thus neglected for calculation.

the microstructure. A subsequent metallographic examination of the remaining specimens showed that small quantities of the precipitants were contained in the DGLs of all castings.

By performing EDX measurements on the precipitates and the iron matrix, the local chemical compositions could be estimated, as shown in Figure 13 exemplarily for the sample GE_II. Although EDX is not suitable to quantitatively determine the lightweight element carbon, the significant absence of silicon and the increased carbon in the precipitates in comparison with the surrounding matrix only permit the conclusion that the phases in question are consisting of cementite.

The precipitation of cementite is caused by the sulfur content of the melt at the melt-coating contact surface. It is known from literature that, in addition to its pearlite-stabilizing effect, sulfur also promotes the formation of cementite during solidification. ${ }^{15}$ Due to local inhomogeneity of the chemical composition of the melt, cementite is stabilized to such an extent that it is preferably precipitated during solidification.

The influence of the cementite precipitants on the mechanical properties should be rather small due to the size of the cementite particles and their rather compacted morphology, especially since the surrounding graphite lamellae represent a much larger and more blatant interruption of the iron matrix.

\section{Conclusion}

This study has shown the chosen approach for the production of SGI "ideal samples" to investigate the influence of the DGL on fatigue resistance of EN-GJS-400-15 and EN-GJS-700-2. The proposed concept for fatigue testing different layers of the samples and their resulting geometry were presented. A casting geometry has been developed which allows the production of samples containing DGLs generated via coated sand cores.

By the application of the specifically designed sulfur core coating, a uniform DGL over the entire contact surface melt/mold was produced. The variations in the layer thickness of the DGLs were appropriate for the molding and casting process utilized and led only in the case of casting GE_II to a slight shortfall to the aimed minimal layer thickness of $500 \mu \mathrm{m}$. This should enable the manufacturing of $400-\mu \mathrm{m}$-thick flat samples for fatigue testing of the DGL microstructure.

Apart from a small number of preexistent, fine cementite precipitates, the iron matrix of the DGLs could be specifically influenced via the illustrated heat treatment routes without changing the graphite morphology of the DGL or the bulk material. As a result, for the EN-GJS-400-15 castings a DGL with a pearlitic microstructure (GE_I), corresponding to the technical normal state, and a DGL with a ferritic matrix (GE_II) could be produced. This is essential for the isolated observation of the influence of the DGL on ferritic SGI.

Even after pearlitization, a thin ferritic flake graphite layer remained in the microstructure of GE_IV (EN-GJS-700-2). Its effect on the fatigue properties of the castings should be minimal since it covers only a small fraction of the DGL microstructure. In addition, further investigations of the segregation effects within this microstructure may provide the possibility to draw additional conclusions about the 
solidification behavior of DGLs and the solid-phase transformation at the bulk material-DGL interface.

In summary, the scientific approach presented here is an important step in the investigation of the influence of DGL on fatigue properties of SGI. Only if various characteristics of the DGL can be examined and understood independently, it will be possible to develop a numerical prediction model for the influence of complex, real casting skins. This is crucial for the enablement of a well-founded integration and consideration of the influences the DGL can have on the properties of castings in the technical design of modern SGI components.

\section{Acknowledgments}

Open Access funding provided by Projekt DEAL. The presented results are derived from IGF Project $18976 \mathrm{~N}$ of the "FVG Research Association of the Foundry Industry" which was funded within the scope of the joint collaborative program "IGF" by the Federal Ministry for Economic Affairs and Energy, following a decision of the German Bundestag. The authors gratefully acknowledge the support, discussions and suggestions provided by the members of the Project Steering Committee. In particular, the members ASK Chemicals $\mathrm{GmbH}$ for providing molding material binders and coatings and Bosch-Rexroth AG for providing printed sand molds for prototype casting trials should be mentioned here.

Open Access This article is licensed under a Creative Commons Attribution 4.0 International License, which permits use, sharing, adaptation, distribution and reproduction in any medium or format, as long as you give appropriate credit to the original author(s) and the source, provide a link to the Creative Commons licence, and indicate if changes were made. The images or other third party material in this article are included in the article's Creative Commons licence, unless indicated otherwise in a credit line to the material. If material is not included in the article's Creative Commons licence and your intended use is not permitted by statutory regulation or exceeds the permitted use, you will need to obtain permission directly from the copyright holder. To view a copy of this licence, visit http://creativecommons. org/licenses/by/4.0/.

\section{REFERENCES}

1. W. Bauer, Untersuchungen über die Störung der Kugelgraphitausbildung in der Randzone von Gusseisen mit Kugelgraphit beim Gießen in mit paraToluolsulfonsäure gehärtete Formsandformen. Gießerei-Praxis 11, 175-183 (1982)
2. G.M. Goodrich, R.W. Lobenhofer, Effect of cooling rate on ductile iron mechanical properties. AFS Trans. 110, 1003-1032 (2002)

3. L.P. Dix, R. Ruxanda, J. Torrance, M. Fukumoto, D.M. Stefanescu, Static mechanical properties of ferritic and pearlitic lightweight ductile iron castings. AFS Trans. 111, 895-910 (2003)

4. S. Boonmee, D.M. Stefanescu, Effect of casting skin on the fatigue properties of CG iron. Int. J. Metalcast. 7, 15-26 (2013)

5. J.R. Davis, ASM Specialty Handbook: Cast Irons (ASM International, 1996), p. 81

6. J. Lacaze, Trace elements and graphite shape degeneracy in nodular graphite cast irons. Int. J. Metalcast. 11, 44-51 (2017)

7. M. Holtzer, M. Górny, R. Danko, The effects of mold/ sand interface phenomena, in Microstructure and Properties of Ductile Iron and Compacted Graphite Iron Castings (Springer, 2015), pp. 3-40

8. S. Boonmee, B. Gyesi, D.M. Stefanescu, Casting skin of compacted graphite iron. Part I: evaluation and mechanism of formation. AFS Trans. 118, 205-216 (2010)

9. D. Stefanescu, S. Wills, J. Massone, F. Duncan, Quantification of casting skin in ductile and compacted graphite irons and its effect on tensile properties. Int. J. Metalcast. 2(4), 7-28 (2008)

10. M. Chisamera, N. Ivan, I. Riposan, S. Stan, Iron casting skin management in No-Bake mould-effects of magnesium residual level and mould coating. China Foundry 12(3), 222-230 (2015)

11. H. Xiaogan, X. Jin, D. Xuqi, W. Yaoke, Nodular iron surface deterioration due to PTSA in resin. AFS Trans. 100, 9-15 (1992)

12. I. Riposan, M. Chisamera, S. Stan, T. Skaland, Surface graphite degeneration in ductile iron castings for resin molds. Tsinghua Sci. Technol. 13, 157-163 (2008)

13. R. Dańko, M. Holtzer, M. Górny, S. ŻymankowskaKumon, Effect of reclamation on the skin layer of ductile iron cast in furan molds. J. Mater. Eng. Perform. 22(11), 3592-3600 (2013)

14. ASTM E2567 - 16a: Standard Test Method for Determining Nodularity and Nodule Count In Ductile Iron Using Image Analysis. ASTM International, West Conshohocken, PA. www.astm.org (2016)

15. S. Kwofie, H.D. Chandler, Potential health effects of locally-manufactured corn-mill grinding plates. J. Sci. Technol. (Ghana) 26(2), 137-147 (2006)

Publisher's Note Springer Nature remains neutral with regard to jurisdictional claims in published maps and institutional affiliations. 